\title{
O JORNAL DIABO COXO (1864-1865): A CARICATURA E A CRÍTICA À ELITE POLÍTICA-SOCIAL NO SEGUNDO IMPÉRIO ${ }^{1}$
}

\author{
Analice Czyzewski ${ }^{2}$ \\ Marcília Rosa Periotto ${ }^{3}$
}

\section{RESUMO}

O jornal Diabo Coxo (1864-1865), publicado por Ângelo Agostini (1843-1910) e Luís Gama (1830-1882) na província de São Paulo, destacou-se por utilizar caricaturas como estratégias na compreensão de fatos sociais e dos interesses de classe emanados tanto da elite local como da vinculação com o governo imperial. A hipótese é de que influenciou na educação política do povo na província paulista a partir das imagens caricatas que ilustravam os fatos cotidianos, da conjuntura social, política e econômica. Esse quadro, com as ilustrações, permitia aos iletrados a compreensão das condições de vida exatamente como se apresentavam na realidade. A imagem e a representação do fato eram suficientes para por o leitor em contato com a realidade e, a partir dela, refletir o significado do cotidiano social e das decisões imperiais e de seus dirigentes. A imprensa do século XIX colaborou e faz parte do conjunto de ações educativas desse período. Nesse sentido, o objetivo deste artigo será discutir como o jornal utilizou-se da caricatura como arma crítica contra as instituições imperiais representantes das forças atrasadas da nação brasileira, transformando-as em subsídio educativo.

Palavras-chave: Jornal Diabo Coxo; Imprensa; Educação; Caricatura.

\section{THE NEWSPAPER “DIABO COXO” (1864-1865): THE CARICATURE AND CRITICISM TO THE SOCIAL POLITICAL ELITE IN THE SECOND EMPIRE.}

\begin{abstract}
The newspaper "Diabo Coxo" (1864-1865), published by Ângelo Agostini (1843-1910) and Luís Gama (1830-1882) in the province of São Paulo, excelled in using caricatures as strategies in the comprehension of social facts and of the class interests emanated from the local elite as well as from the connection with the imperial government. The hypothesis is that it influenced on the political education of the people in the province of São Paulo from the caricatured images which illustrated the everyday facts, of the social conjuncture, political and economical. This picture, with the illustrations, enabled the illiterates the comprehension of life conditions exactly as they would be presented in the reality. The image and the fact representation would be enough to put the reader in contact with the reality and, from it, reflect the meaning of the social daily routine and of the imperial and its leaders decisions. The XIX century press collaborated and it is part of the series of educational actions from this period. In this sense, the aim of this article will be to discuss how the newspaper made use of the caricature as a critical weapon against the imperial institutions representatives of the dated powers of the Brazilian nation, transforming them into educational subsidies.
\end{abstract}

Key words: Diabo Coxo, newspaper, Press - Education, caricature.

\section{INTRODUÇÃO}

O texto busca afirmar a importância da imprensa no registro histórico do cotidiano social, político e econômico no século XIX. Essa condição, de fonte importante aos 
estudos de História da Educação, é reconhecida em razão de a imprensa ter produzido debates os quais contribuíram na formação cultural e política do povo.

O jornal Diabo Coxo, objeto do estudo, não teve vida longa, contudo, a historiografia o reconheceu como pioneiro na veiculação de caricaturas, traçadas no firme objetivo de expor ao máximo a ineficiência do regime imperial, ridicularizando os seus atores e dando a eles o retrato exato do que representavam e no modo de agir frente às demandas progressistas.

Apresenta-se o conceito sobre caricatura e os elementos teóricos e conceituais que a referendam como instrumento educativo. As caricaturas com as quais o Diabo Coxo fustigou as instituições imperiais e as elites concederam a ele o papel de agente educativo não somente por ter retratado criticamente o quadro econômico, político e social, mas, principalmente, por revelar que a dinâmica das relações sociais, estruturadas no poder de mando e assentada na naturalização das diferenças de classe não permitia a opinião pública perceber como a realidade concreta da população.

\section{O JORNAL DIABO COXO COMO AUXILIAR NO PROCESSO EDUCATIVO DOS PAULISTAS}

O estudo acerca do caráter educativo presente no jornal Diabo Coxo e a apreciação do contexto social do século XIX, especialmente o período de sua atuação (1864-1865), permite levantar a hipótese de que a caricatura foi um dos instrumentos utilizados no objetivo de instruir politicamente a população da província paulista, pois por meio delas apontou os debates e questões enfrentadas por sua época.

A análise realizada sob a perspectiva teórica, na qual as lutas humanas são o ponto de partida, conduz a uma visão abrangente e aprofundada dos condicionantes vinculados à materialidade da produção humana. Permite, em última instância, identificar as bases utilizadas pelos formadores de opinião pública, aliados à defesa do progresso e em nome de mudanças favoráveis a melhoria da sociedade.

Visto por esta perspectiva, o Diabo Coxo agiu no sentido de formar a opinião pública e seguiu à risca os propósitos da imprensa combativa e, ao mesmo tempo, incorporou ao debate a imagem de uma sociedade enlaçada às formas do passado, incapaz de modernizar-se e de incluir o povo num projeto cuja natureza, desde sempre, era manterse elitista.

Contudo, é preciso enfatizar o sentido que se atribui ao caráter educativo vinculado à imprensa, de modo geral, e ao Diabo Coxo em particular. O debate educativo implícito aos temas tratados, visando civilizar e incluir o Brasil numa presumida rota de desenvolvimento e progresso, esteve presente em muitos jornais durante o século XIX. Alguns deles foram mais enfáticos nessa defesa, inclusive se denominando órgão do progresso social, como é o caso da revista O Progresso ${ }^{4}$, dirigida por Antonio Pedro de Figueiredo. Ao analisar esta revista, Periotto (2001), num estudo sobre imprensa e educação no século XIX, faz uma afirmação possível de utilizá-la na explicitação de novos estudos na área:

A análise [...] tem por propósito privilegiar os aspectos formativos presentes [...] - entendidos enquanto a postulação criteriosa de ideias que intencionavam encaminhar os homens daquele meado de século à conquista do progresso -, ensejados no transcorrer de sua atuação junto à opinião pública [...] se seu propósito era instruir os homens de seu tempo 
[...] temos que considerar a iminência de um processo educativo em curso (PERIOTTO, 2001, p. 3-4).

A ação educativa, portanto, se fazia também no ato civilizatório de levar ideias, propostas, enfim, uma nova visão de mundo a quem estava envolvido pelas velhas formas sociais e encontrava-se alheio às inovações nascidas do avanço tecnológico e dos melhoramentos, que o estender do progresso trazia à vida das pessoas.

A História da Educação, neste sentido, é favorecida com a eleição de novos objetos e novas abordagens teórico-metodológicas, além de ser reveladora de um longo processo educativo não escrito nos bancos escolares, o foi no interior da dinâmica social no século XIX, mudando-a ao sabor das necessidades e potencialidades disponíveis. Afirmam Faria Filho, Chamon e Rosa (2006) que:

Já há muitos anos, diz-se que a pesquisa em história da educação passa por uma intensa renovação. Mesmo considerando a enorme fascinação do campo pedagógico pelo novo, logo produzido como positivo, no caso da história da educação, ao que tudo indica, a renovação tem significado um enriquecimento das abordagens teórico-metodológicas, uma ampliação das fontes, a diversificação dos objetos e a elaboração de perguntas inimagináveis há algumas décadas. No seu conjunto, tais procedimentos têm redimensionado o nosso campo de estudos (FARIA FILHO; CHAMON; ROSA, 2006, p. 7).

Parte dos novos procedimentos da historiografia educacional e dos novos objetos em análise, o Diabo Coxo, periódico utilizado como fonte de pesquisa, evidencia-se pelo impacto da imagem numa sociedade composta, na sua maioria, por uma população analfabeta e na qual a caricatura pode ser utilizada como recurso e propósito educativo.

O conceito de caricatura é diverso, o que impede estabelecer um consenso acerca de seu significado. Essa dificuldade, porém, pode ser superada quando se considera o alcance das imagens junto à compreensão dos indivíduos, o seu conteúdo e a capacidade de uma sociedade se autorretrar nos limites da sátira e da provocação do riso. Nesse sentido, Lobato (1946) assegura que "Em nada se estampa melhor a alma de uma nação, do que a obra de seus caricaturistas. Parece que o modo de pensar coletivo tem seu resumo nessa forma de riso" (LOBATO, 1976, p. 38).

Os estudos sobre essa questão, de forma geral, reconhecem a influência da caricatura na formação da opinião pública na medida em que elas simplificam a compreensão daquilo que está em realce, como também os significados ocultos nos traços do artista. De acordo com Santos (2000):

A imprensa não prescinde da colaboração da caricatura e do humorismo
[...] As grandes causas em jogo têm sempre no lápis do artista e no humor
a defesa segura, a propaganda mais eficaz do que o gongorismo de muitos
artigos de fundo. O humorismo no homem, assim como seu desejo de
distrair-se e de rir, está tão enraizado em sua natureza que não
concebemos a humanidade sem essa vontade de pilheriar em suas
atitudes, mesmo as mais sérias (SANTOS, 2000, p. 11).

A fim de evitar possíveis incongruências ou falsas inferências acerca do tema, optou-se por apresentar alguns dos diversos sentidos e significados do termo. A origem etimológica da palavra está no verbo italiano caricare, que significa carregar, 
sobrecarregar ou carregar exagerando. Geralmente quando se pensa em caricatura logo se remete ao sentido de cara ou fisionomia de algo ou de alguém. Na desconstrução dessa associação Cagnin (1994) afirma que:

[...] só nos países de fala portuguesa é possível supor que a palavra 'caricatura' seja derivada de 'cara', e, em conseqüência, que caricatura não seja outra coisa senão um retrato, uma representação humorística da cara, em que se ressaltam os traços característicos, sobretudo os defeitos faciais, para provocar o riso, quando não ferir com a sátira mordaz e o deboche. [...] Certamente a cara, o rosto, presente em quase todos os desenhos de humor, por ser a figura humana extremamente familiar, consolidaram este conceito equivocado, hoje tão radicado entre nós, de supor que a palavra 'cara' tenha dado origem à palavra 'caricatura' (CAGNIN, 1994, p. 6).

Há no Dicionário Aurélio (FERREIRA, 2008) duas definições para o termo caricatura: a primeira se refere ao desenho que acentua ou revela certos aspectos das pessoas ou dos fatos; a segunda a define como a reprodução deformada de algo. Comparou-se esse conceito, que pode ser definido como simples ou usual, ao conceito disponível na Enciclopédia INTERCON ${ }^{5}$ de Comunicação, que reuniu nesta obra os conceitos indispensáveis à área, dentre eles a definição de "caricatura". O conceito evidência o caráter político e ou social contido nas imagens, principalmente a crítica dirigida em tom satírico aos homens públicos.

A caricatura, como retrato satírico, surge a partir da obra de Agostino Carracci, no final do século XVI. A família Carracci mantinha uma academia em Bolonha, tendo como uma das suas principais atividades a pintura de gênero, voltada a cenas do cotidiano (HERMES, 2012, p. 4).

O gênero caricatura, sob o ponto de vista da expressão que o liga ao humor gráfico, abarca as categorias relativas ao humor e ao riso de uma forma geral, portanto, é dentro desta expressão que está contido o conceito que define a caricatura, a charge, o cartum e a história em quadrinhos (GAWRYSZEWSKI, 2008).

Para Lima (1963), a caricatura só encontra sentido quando exposta ao coletivo de uma sociedade, portanto, é presente em seu conceito as dimensões sociais e políticas. Assim, a caricatura assume a função de "caracterizar, sublinhar algum gesto, para notar algum jogo de fisionomia, para unir tão intimamente todos os aspectos inesperados, inéditos, da máquina humana, que o envoltório da carne e dos ossos revele todos os seus segredos" (LIMA, 1963, p. 6).

No Diabo Coxo as caricaturas enquadram-se na categoria de charge política e social, reiterando sua função educativa junto à população ao tratar de temas de interesse coletivo. Nesse espaço e contexto, a imprensa, como agente colaborador no processo educativo da nação, mesmo informalmente, sem estar apoiada na didática pedagógica inerente à atividade educativa das instituições formais de ensino, conduziu o processo educativo no que se refere às massas, atendendo à demanda de sua época.

[...] As caricaturas e as charges realizadas pelo ítalo-brasileiro, Ângelo Agostini, no Brasil, durante o século XIX, refletiam a insatisfação para com o governo de D. Pedro II. Representação da figura humana [...] composta por traços anatômicos exagerados e distorcidos [...] a caricatura 
é uma "representação plástica ou gráfica de uma pessoa, ação ou ideia interpretada [...] sob seu aspecto ridículo ou grotesco". A charge normalmente uma sátira ou crítica política - é um comentário ilustrado feito com base em um fato recente que tenha se tornado notícia [...] (GALLOTTA, 2007, p. 161).

A imprensa indicava a necessidade de escolas de primeiras letras à medida do robustecimento do debate pela modernização, tornando imprescindível a criação de um sistema educacional que contribuísse com o projeto civilizador e propiciasse o progresso. Ganhou visibilidade social o jornal de Agostini e cativou um público leitor fiel, ainda que vinculado ao público letrado, mas também ao público em geral que, mesmo analfabeto, "ouvia" e "via as imagens":

Ao noticiar ações relevantes à difusão e consolidação do sistema educativo no Brasil a imprensa acabou por se tornar aliada da escola, conduzindo um debate que cobrava por reformas e modernização das instituições sociais, já ultrapassadas no mundo desenvolvido, mas vigentes no Brasil.

$\mathrm{Na}$ perspectiva comunicacional, as palavras traduzidas em signos ampliaram as possibilidades de comunicação entre os homens. A imagem gráfica jamais deixou de ter papel expressivo na comunicação humana, uma vez que o acesso à leitura aconteceu de forma gradativa e atingia apenas as classes mais privilegiadas da sociedade. Assim, a imprensa conquistaria um novo tipo de leitor, uma camada não privilegiada que compreenderia, via imagem gráfica, um novo modo de perceber os acontecimentos através de processos mais explicativos e atrativos (SANCHOTENE, 2011, p. 5).

De forma mais ampla, pensar a imprensa do século XIX, segundo Pallares-Burke (1998), é considerar os jornais produzidos no Brasil nesse período propagando os valores e as ideias iluministas, a fim de educar o público para o projeto civilizador moldado no estatuto das relações burguesas. Tratava-se, enfim, de universalizar um modo de ser vigente nas nações desenvolvidas:

Na verdade, o projeto iluminista de transformar mentalidades "arcaicas" em "ilustradas" não só se revela presente como até reforçado no jornalismo latino-americano do século XIX. [...] Recém-emancipada da ordem política absolutista a imprensa passa a ser constantemente referida como meio mais eficiente e poderoso de influenciar os costumes e a moral pública, discutindo questões sociais e políticas. De existência em geral efêmera, os novos periódicos [...] aparecem em profusão em toda América Latina e se auto descrevem como indispensáveis "difusores de luz", veículos da cultura, progresso e liberdade. Tal função insubstituível da imprensa é geralmente justificada pela ausência de outros agentes educativos, como leis e um sistema de educação pública, que, caso existente, poderiam fazer mais sistemática e formalmente o que o jornalismo fazia informalmente (PALLLARES-BURKE, 1998, p. 147).

A caricatura e a charge são desenhos de cunho humorístico. A primeira pretende exaltar características fisionômicas de modo a revelar a personalidade humana. A segunda remete aos fatos reais que tradicionalmente se encontram ligados à realidade política e econômica de uma sociedade. É possível concluir que a obra de Agostini contém as duas 
características, a caricatura e a charge, que estão estritamente ligadas ao humor. De acordo com Pires (2010):

O cômico (representado por charges e caricaturas) passa da condição de mero instrumento de entretenimento para ser compreendido como um mecanismo de elaboração e reflexão social, bem como pode ser entendido como um modo discursivo de resistência ou exprimir, através da ironia, as críticas às instituições formais e aos grupos políticos estabelecidos, sugerindo a existência de campos de tensão discursivos (PIRES, 2010, p. 9).

Em relação ao traço, a caricatura retrata os tipos humanos por meio da representação gráfica disforme e exagerada, geralmente com figuras narigudas, orelhudas, cabeçudas, enfim, chamativas por serem e assim por diante. Hermes (2012) esclarece sobre as características contidas no desenho:

As caricaturas remetem diretamente às personalidades representadas. É na maneira como as relações de semelhança são estabelecidas, contudo, que está a sua geração de significados mais relevantes, acentuando ou alterando um ou outro aspecto qualitativo dessas figuras humanas. Distorções são comuns em caricaturas, gerando um efeito cômico, acentuando um ou outro aspecto da fisionomia (HERMES, 2012, p. 3).

$\mathrm{Na}$ charge, as imagens e grafismos buscam o resumo das situações reais que ocorrem na política e na sociedade. Ambas são geradoras de críticas e, especificamente sobre a charge política, a caricatura política "vai além do simples conceito de caricatura como traços característicos e físicos do personagem; engloba preocupações sociais e políticas daquele que produz a arte, ou seja, um profissional engajado" (GAWRYSZEWSKI, 2008, p. 13).

A caricatura, incontestavelmente, possibilita verdadeira incursão no procedimento moral, físico e mental dos caricaturados, sendo o mais perfeito, minucioso e indelével relatório do caráter da sociedade de qualquer tempo. [...] Todo sentimento humano e universalidade da obra dos caricaturistas não provocam apenas o riso, porque fazem pensar (COTRIN, 1965, p. 10).

Em outras palavras, a imprensa retratou os hábitos e costumes da sociedade e permitiu a circulação dos personagens que compunham o arranjo social por meio do humor e da irreverência, papel desempenhado pelas imagens: "A introdução da caricatura na imprensa é marcada por avanços tecnológicos, através da litografia, assim como a popularização dos jornais como veículos e fontes de informação pública" (SANCHOTENE, 2011, p. 18).

A saída do jornal Diabo Coxo às ruas foi um dos marcos na conexão entre a imprensa e a educação no Brasil do século XIX. Seus idealizadores propuseram um pacto com a sociedade: "A imprensa, maior inimiga dos maus, é a única força que encontro na terra para desmascarar a esses entes criminosos ou ridículos estúpidos ou orgulhosos" (DIABO COXO, 1864, n. 1, Série 1, p. 2). Apesar de não se tratar de um periódico específico sobre a educação, os elementos nele contidos tais como as caricaturas, os textos satíricos e poéticos, permitem entender as vinculações históricas necessárias à apreensão 
do processo educativo que apontava para um estreitamento da relação entre saber e progresso:

\begin{abstract}
Para parcela dos sujeitos que viveram no Império do Brasil, a imprensa era fundamental na vida política. Surgidos no Primeiro Reinado, os jornais difundiram-se pelas províncias, tornando-se presentes no cotidiano das pessoas em lugarejos diversos, por vezes ligados por caminhos ínvios, redefinindo as posições que os sujeitos tinham de si e do mundo que os cercava. Ao passo que se organizavam os espaços do debate político propriamente dito, a imprensa caminhava, modificando as relações que os indivíduos estabeleciam com os poderes e instituições locais (MOREIRA, 2011, p. 141).
\end{abstract}

As caricaturas de Agostini inclusas no Diabo Coxo são reconhecidas pela historiografia como o primeiro conjunto de recursos iconográficos que circulou na província de São Paulo. Neste sentido, afirma-se que o desenhista era coerente com a dinâmica social e conduziu um primeiro contato dos leitores com a realidade efetiva da província paulista. Se em época anterior às imagens os indivíduos contavam unicamente com os rudimentos concedidos pela alfabetização, a partir daquele momento a caricatura lhes concedia uma nova possibilidade de compreensão da realidade vivida, já que "a elite era uma ilha de letrados num mar de analfabetos", segundo Carvalho (1996, p. 55).

Desse modo, ultrapassou por meio das imagens a pequena "ilha de letrados", colaborando com a formação do público leitor, pois as obras literárias que vinham do exterior não atingiam as camadas populares. Nesse sentido, consideram-se as imagens componentes que contribuíram na apropriação dos elementos sociais e culturais da província paulista. Para Lajolo e Zilberman (1996):

Se, na Europa, livros publicados já no século XVI (ou até antes) textualizavam o leitor [...] no Brasil, é só a ficção romântica que os esforços nessa direção mostram-se visíveis. [...] Só no ano de 1840 o Brasil do Rio de Janeiro, sede da monarquia, passa a exibir alguns traços necessários para a formação e o fortalecimento de uma sociedade leitora: estavam presentes os mecanismos mínimos para a produção e circulação da literatura, como tipografias, livrarias e bibliotecas; a escolarização era precária, mas manifestava-se o movimento visando a melhoria do sistema; o capitalismo ensaiava seus primeiros passos graças à expansão da cafeicultura e dos interesses econômicos britânicos, que queriam um mercado cativo, mas em constante progresso (LAJOLO; ZILBERMAN, 1996, p. 18).

Diante do exposto entende-se o jornal Diabo Coxo como um partícipe de peso no processo civilizatório necessário a entrada em definitivo das relações burguesas no Brasil, sobrepujando os aspectos remanescentes do mundo colonial que se constituíam obstáculos ao progresso material. É certo, porém, que a ação do jornal esteve limitada à província de São Paulo onde fundou em 1866 o jornal Cabrião, no qual fazia ataques ao clero e a elite escravocrata da província paulistana. No entanto só alcançou um público maior quando se mudou para o Rio de Janeiro e fundou a Revista Ilustrada em 1876, uma publicação que satirizava a elite, e que veio a somar com os demais jornais de Agostini como importantes órgãos de imprensa no âmbito do debate sobre a república, libertação dos escravos e adoção daquelas condições que poderiam permitir ao Brasil um desenvolvimento mais consequente do que havia até então. 


\section{CONCLUSÃO}

Com o estudo desenvolvido, contata-se que se os letrados, políticos liberais e conservadores no Brasil do século XIX tinham consciência da contemporaneidade das questões da abolição, república e da educação, entendidas por muitos como essenciais ao progresso e desenvolvimento, por qual motivo às iniciativas para resolvê-las não foram e nem puderem ser tomadas desde o início do Segundo Império?

As contradições do Segundo Império pulsavam na sociedade brasileira, a elite agrária, detentora do poder político era favorável à Monarquia Constitucionalista, o que lhe proporcionava não correr riscos nem abrir mão dos privilégios de que gozara até então. Contudo, essa forma de organização social e produtiva era incompatível com a organização imposta pelo sistema capitalista nos demais países. O resultado da "resistência" conferiu ao Brasil o adjetivo de país atrasado.

Sendo assim, no debate empreendido pelo Diabo Coxo, opositor à manutenção do sistema monárquico e escravista, as questões colocadas ao público permitiam uma visão ampla e destacavam os reais motivos pelos quais o país não empreendia medidas efetivas rumo à modernidade. Desse entendimento decorre a afirmação que a caricatura pode ser utilizada como arma educativa, auxiliando na compreensão das questões de sua época e permitindo aos não alfabetizados uma visão de mundo, circunscrita aos aspectos locais, que não correspondia à realidade política e social da sociedade brasileira do período.

\section{Referências}

AGOSTINI, Angelo. O Diabo Coxo. São Paulo: EDUSP, 2005 (Edição fac-similar).

CAGNIN, Antonio Luiz. 130 anos do Diabo Coxo: o primeiro periódico ilustrado de São Paulo, 1864-1994. Comunicação e Educação, São Paulo, v. 1, p. 15-46, set. 1994.

CARVALHO, José Murilo. A construção da ordem: a elite política imperial: teatro de sombras: a política imperial. 2. ed. rev. Rio de Janeiro: Editora UFRJ, Relume Dumará, 1996.

COSTA, Camilo F. Riani-. Linguagem \& Cartum... tá rindo do quê? In: INTERCOMSBEIC. Anais. XXV Congresso Brasileiro de Ciências da Comunicação. Salvador/BA, 1 a 5 set 2002. Disponível em:

http://www.portcom.intercom.org.br/pdfs/69208210912106167039727179422688187903. pdf

COTRIN, Álvaro. O Rio na Caricatura. Exposição organizada pela Seção de Exposições da Biblioteca Nacional e patrocinada pelo Jornal do Brasil, como contribuições aos festejos do $4^{\circ}$ Centenário da Cidade. Rio de Janeiro: Biblioteca Nacional, 1965. Disponível em: <http://objdigital.bn.br/acervo_digital/div_iconografia/ icon693341.pdf >. Acesso em: 20 jul. 2015.

ENCICLOPÉDIA INTERCOM DE COMUNICAÇÃO. São Paulo: Sociedade Brasileira de Estudos Interdisciplinares da Comunicação, 2010. Disponível em: <http://www. ciencianasnuvens.com.br/site/wp-content/uploads/2013/07/Enciclopedia-Intercom-deComunica\%C3\%A7\%C3\%A3o.pdf >. Acesso em: 20 jul. 2014. 
FARIA FILHO, Luciano Mendes; CHAMON, Carla Simone; ROSA, Walquiria Miranda. Educação Elementar: Minas Gerais na primeira metade do século XIX. Belo Horizonte: UFMG, 2006.

FERREIRA, Aurélio Buarque de Holanda. Dicionário Aurélio. 7. ed. Curitiba: Editora Positivo, 2008.

GALlotTA, B. Ciro. Humor nos periódicos paulistanos: o Diabo Coxo (1864-1865) e o Cabrião (1866-1867). Intercon - Sociedade Brasileira de Estudos Interdisciplinares da Comunicação, São Paulo, p. 1-12, maio/jun. 2007.

GAWRYSZEWSKI, Alberto. Conceito de caricatura: não tem graça nenhuma. Domínios da Imagem, Londrina, ano 1, n. 2, p. 7-26, maio 2008.

HERMES, Gilmar Adolfo. As ilustrações jornalísticas: definição e história. In: ENCONTRO NORDESTE DE HISTÓRIA DA MÍDIA, 2., 2012. Teresina. Anais... : Teresina: EDUFPI, 2012. p. 1-15.

LAJOLO, Marisa; ZILBERMAN, Regina. A formação da leitura no Brasil. São Paulo: Ática, 1996.

LIMA, Herman. História da caricatura no Brasil. Rio de Janeiro: José Olympio, 1963.

LOBATO, Monteiro. Idéias de Jeca Tatu. São Paulo: Brasiliense Limitada, 1946.

MOREIRA, Luciano Silva da. Imprensa e opinião pública no Brasil Império: Minas Gerais e São Paulo (1826-1842). 2011. 264 f. Tese (Doutorado em História) - Faculdade de Filosofia e Ciências Humanas da Universidade Federal de Minas Gerais, Belo Horizonte, 2011.

PALLARES-BURKE, Maria Lucia G. A imprensa periódica como uma empresa educativa no século XIX. Caderno de Pesquisa, São Luis: UFMA, n. 104, p. 144-161, jul. 1998.

PERIOTTO, Marcília Rosa. A espiral do progresso e a felicidade da nação. 2001. $201 \mathrm{f}$. Tese (Doutorado em Educação) - Faculdade de Educação, Universidade Estadual de Campinas, UNICAMP, Campinas, SP, 2001.

PIRES, Maria da Conceição Francisca. Ângelo Agostini na história das ideias e dos intelectuais do Brasil. In: SEMINÁRIO NACIONAL DE HISTÓRIA DA HISTORIOGRAFIA: TEMPO PRESENTE \& USOS DO PASSADO, 4., 2010, Ouro Preto. Cadernos de Resumo... Outro Preto: EdUFOP, 2010. p. 1-11.

SANCHOTENE, Carlos Renan Samuel. Mídia, humor e política: a charge da televisão. Rio de Janeiro: E-papers, 2011.

SANTOS, Délio Freire dos. Introdução. In: AGOSTINI, Ângelo; CAMPOS, Américo de; REIS, Antônio Manoel dos. Cabrião: semanário humorístico: 1866-1867. 2. ed. rev. e ampl. São Paulo: Editora UNESP, Imprensa Oficial do Estado, 2000. p. 11-14.

RAMOS, Everardo. Origens da imprensa ilustrada brasileira (1820-1850): imagens esquecidas, imagens desprezadas. Rio de Janeiro: Fundação Casa de Rui Barbosa, 2008. 


\section{Notas}

${ }^{1}$ O texto é parte da dissertação de mestrado "O Poeta do Lápis": o jornal Diabo Coxo e a ação educativa da imprensa nos anos de 1864 a 1865, apresentada ao Programa de Pós-Graduação em Educação da Universidade Estadual de Maringá e defendida em abril de 2015.

${ }^{2}$ Mestrado- UEM.

${ }^{3}$ Doutorado- UNICAMP.

${ }^{4}$ A revista $O$ Progresso, de Antonio Pedro de Figueiredo, foi publicada em 12 de julho de 1846 na cidade do Recife-PB. Trazia a seguinte inscrição; "revista social, política, literária e científica O Progresso, órgão das ideias de progresso social na América do Sul". Em 1950, a Imprensa Oficial do Estado de Pernambuco, sob a organização do professor Amaro Quintas, publicando-a como parte do programa de comemorações do centenário da Rebelião Praieira.

${ }^{5}$ Cumpre esclarecer que para compor a Enciclopédia INTERCON, foram convidados diversos autores para conceituar os inúmeros verbetes referentes à área de comunicação e jornalismo. Utilizamos deste conjunto o conceito de caricatura elaborado por Camilo Riani.

Recebido: agosto-15 $\quad$ Aprovado: setembro-15 